\title{
The Same Magnocellular Neurons Send Axon Collaterals to the Posterior Pituitary and Retina or to the Posterior Pituitary and Autonomic Preganglionic Centers of the Eye in Rats
}

\author{
Ágnes Csáki ${ }^{1}$, Katalin Köves ${ }^{1, *}$, Zsolt Boldogkői ${ }^{2}$, Dóra Tombácz ${ }^{2}$ and Zsuzsanna E. Tóth ${ }^{1}$ \\ 1 Department of Anatomy, Histology and Embryology, Faculty of Medicine, Semmelweis University, \\ H-1085 Budapest, Hungary; csaki.agnes@med.semmelweis-univ.hu (Á.C.); \\ toth.zsuzsanna.emese@med.semmelweis-univ.hu (Z.E.T.) \\ 2 Department of Medical Biology, Faculty of Medicine, University of Szeged, H-6720 Szeged, Hungary; \\ boldogkoi@gmail.com (Z.B.); tombacz.dora@med.u-szeged.hu (D.T.) \\ * Correspondence: koves.katalin@med.semmelweis-univ.hu; Tel.: +36-1-215-6920 (ext. 53618); \\ Fax: +36-1-215-6034
}

Citation: Csáki, Á.; Köves, K.; Boldogkői, Z.; Tombácz, D.; Tóth, Z.E. The Same Magnocellular Neurons Send Axon Collaterals to the Posterior Pituitary and Retina or to the Posterior Pituitary and Autonomic Preganglionic Centers of the Eye in Rats. NeuroSci 2021, 2, 27-44. https://doi.org/10.3390/ neurosci2010002

Received: 17 December 2020

Accepted: 17 January 2021

Published: 20 January 2021

Publisher's Note: MDPI stays neutral with regard to jurisdictional claims in published maps and institutional affiliations.

Copyright: (c) 2021 by the authors. Licensee MDPI, Basel, Switzerland. This article is an open access article distributed under the terms and conditions of the Creative Commons Attribution (CC BY) license (https:// creativecommons.org/licenses/by/ $4.0 /)$.

\begin{abstract}
In rats, some parvocellular paraventricular neurons project to spinal autonomic centers Using the virus tracing technique, we have demonstrated that some magnocellular paraventricular neurons, but not supraoptic neurons, also project to autonomic preganglionic centers of the mammary gland, gingiva, or lip. A part of these neurons has shown oxytocin immunoreactivity. In the present experiment, we have examined whether the same magnocellular neuron that sends fibers to the retina or autonomic preganglionic centers of the eye also projects to the posterior pituitary. Double neurotropic viral labeling and oxytocin immunohistochemistry were used. After inoculation of the posterior pituitary and the eye with viruses, spreading in a retrograde direction and expressing different fluorescence proteins, we looked for double-labeled neurons in paraventricular and supraoptic nuclei. Double-labeled neurons were observed in non-sympathectomized and cervicalsympathectomized animals. Some double-labeled neurons contained oxytocin. After the optic nerve was cut, the labeling did not appear in the supraoptic nucleus; however, it could still be observed in the paraventricular nucleus. In the paraventricular nucleus, the double-labeled cells may be the origin of centrifugal visual fibers or autonomic premotor neurons. In the supraoptic nucleus, all double-labeled neurons are cells of origin of centrifugal visual fibers.
\end{abstract}

Keywords: rat; virus tracing; immunohistochemistry; centrifugal visual

\section{Introduction}

Two retinofugal systems have long been known by researchers. One of them is the classical visual system [1], and the other one is the retinohypothalamic tract [2,3]. In 1893, Ramon Y Cajal [4] discovered fibers in the retina, which, according to his opinion, might originate from the central nervous system. These fibers were named centrifugal visual fibers. Repérant and coworkers [5] overviewed the data concerning the centrifugal visual system. It was found that "the centrifugal visual fibers do not form a homogenous system, rather they form at least eight subsystems". Vereczki and her coworkers [6] injected biotinylated dextran amine (BDA) into the vitreous body of the eye of rats. They found BDA-containing neurons in supraoptic (SON) and paraventricular (PVN) nuclei, besides several forebrain structures. It was concluded that these labeled neurons might be the cells of origin of centrifugal visual fibers.

Ample evidence indicates that hypothalamic nuclei are involved in the control of autonomic innervation of various organs. First, nontranssynaptic tract-tracing techniques were used; it was found that some parvocellular PVN (pPVN) neurons project to the spinal cord. Secretory granules were not found in these neurons [7]. Swanson and Kuypers [8] 
described three subdivisions in the pPVN that project to the spinal intermediolateral cell column (IML). Later, it was demonstrated that these "spinal-projecting autonomic neurons (SPANs)" contained dynorphin, enkephalin, oxytocin (OT), or arginin vasopressin (AVP) mRNA [9]. Cholera toxin was injected into the spinal cord, and in situ hybridization was used to identify neuropeptides in the labeled hypothalamic neurons. The majority of SPANs were located in the ventral and lateral part of the pPVN. A limited number of cholera-toxin-labeled neurons were also found in the magnocellular part of the PVN (mPVN).

Pyner and Coote [10] injected two different fluorescent neuroanatomical tracers, FluoroGold (FG) and FastBlue (FB) or dextran tetramethylrhodamine (DR), into the rostral ventrolateral medulla (rVLM) and second thoracic segment (T2) of the spinal cord. Most double-labeled neurons were found in the mid-rostral pPVN. The axons of these neurons branch and innervate neurons in both rVLM and the spinal cord. Another research group showed that the same PVN neuron sent axonal collaterals to both the dorsal vagal complex (DVC) and the arcuate nucleus (ARC). These nuclei are involved in the regulation of feeding. In this study, after the injection of different retrograde tracers into the DVC and ARC, double-labeled neurons were found in the PVN. About $50 \%$ of labeled cells exhibited nesfatin immunoreactivity [11].

In the last three decades, the transsynaptic virus tracing method has become commonplace alongside classical tract-tracing methods. Strack and coworkers [12] simultaneously injected a retrograde pseudorabies virus into different sympathetic ganglia and the adrenal gland. It was generally found that premotor sympathetic neurons were observed in the hypothalamic PVN and the perifornical area (Pf). These cell groups regulate the entire sympathetic outflow. In our previous experiment, it was shown that a retrograde spreading virus administered to the mammary gland [13], lower gingiva, or lower lip [14] appeared in the corresponding portion of the IML and brain stem and some oxytocinergic and vasopressinergic neurons of the PVN. Gerendai and her coworkers [15] described PVN neurons that simultaneously innervate the left adrenal gland and the left ovary. It was postulated that the same PVN neuron sent axon collaterals to two different target tissues. Additionally, Hettigoda and coworkers [16], using double virus labeling, identified neurons in several brain regions that project to the submandibular gland via both sympathetic and parasympathetic efferent pathways. They supposed that these are "common command neurons that coordinate autonomic regulation of the submandibular gland".

The chemical coding of the above-mentioned neurons has not been identified. Nearly fifty years ago, it was discovered that OT neurons project not only to the posterior pituitary (PP) but to several structures of the central nervous system (Buijs, 1979). In recent years, it was also shown that there are several different types of OT neurons in the hypothalamus [17] that project to the PP, forebrain structures, brainstem, and spinal cord. A few years ago, it was demonstrated [18] that the axons of the same magnocellular OT neurons bifurcate and send collaterals to the central amygdala and the PP. According to the recent standpoint, the mPVN neurons project to more than 50 forebrain regions and simultaneously terminate in the posterior pituitary [17]. Althammer and coworkers [19] reviewed the similarities and discrepancies of oxytocinergic modulation in rodents and primates. In the central nervous system, the sites of OT synthesis, as well as projections of OT axons, largely overlap in rodents and primates; however, there are fundamental differences in OT receptor expression and OT-mediated behaviors $[19,20]$. The results of three rodents and three primates were compared (voles, rats, and mice vs. rhesus monkeys, titi monkeys, and marmosets). In rodents (macrosmatic animals), the receptors are found in the olfactory bulb, anterior olfactory nucleus, nucleus accumbens, ventral pallidum, lateral septum, preoptic area, medial amygdala, bed nucleus of stria terminalis, hippocampus, anterior hypothalamic area, ventromedial nucleus, ventral tegmental area, and periaqueductal gray matter. In primates, the OT receptors are located more caudally than in rodents, mainly in the nucleus accumbens, nucleus basalis Meynert, superior colliculus, ventromedial nucleus, the midbrain, and pons. OT receptors are located on neurons that have very 
different chemical natures, and they can exert the fine-tuning of neuronal networks that are involved in social recognition, pair-bonding, stress, food intake, fear, trust, empathy, and xonophobia.

No convincing data are available in the literature about whether the same posterior pituitary projecting neurons (PPPNs) send axon collaterals to the preganglionic autonomic neurons of the eye, located in the Edinger-Westfal $(E-W)$ nucleus or the IML of the spinal cord. Nothing is known about whether the PPPNs also give rise to centrifugal visual fibers.

In our present experiment, the above-mentioned possibilities were investigated using the dual virus track tracing method. After inoculation of the PP with a virus and the inoculation of the eye with viruses expressing different fluorescence proteins (green: Ka-gEImemGFP-RV; red: Ka-Vhs-memCherry-A-RV or Ka-Vhs-CHR-memTomato- $A-R V)$, we looked for double-labeled neurons in the PVN and SON. With the use of immunohistochemistry, we also examined whether the double-labeled neurons contained OT. The reason for this experiment is that OT has been described in the extracellular matrix between the retinal cones and OT receptors have been demonstrated on the retinal pigment epithelium [21,22], but the origin of OT has not been identified. We wanted to find out whether there are enough OT neurons, which project to the retina, and whether they could explain the source of this peptide. As it has clearly been shown that AVP has an intrinsic system in the retina [23], we did not examine AVP immunoreactivity in the double-labeled neurons.

\section{Materials and Methods}

\subsection{Animals}

Adult Wistar male and female rats (2-3-month-old), kept in a light- and temperaturecontrolled vivarium (light on from 6 a.m. till 6 p.m.; $22 \pm 2{ }^{\circ} \mathrm{C}$ ), were used for the experiments. The animals were treated according to the rules of EU Directive 2010/63/EU (Permission \#22.1/1158/3/2010).

\subsection{Viruses Used for Inoculation}

Three pseudorabies virus strains were used (constructed by the coauthors Zsolt Boldogkói and Dóra Tombácz). Ka-gEI-memGFP-RV could spread only in a retrograde direction and expressed green fluorescence protein (GFP). Ka-Vhs-memCherry- $A-R V$ or KaVhs-CHR-memTomato- $A-R V$ could be transported in both ante- and retrograde directions and expressed red fluorescence protein (Cherry or Tomato). The viruses were kept on Medusa cells in a DMEM solution (Gibco/Thermo Fisher Scientific, Waltham, MA USA), supplemented with $5 \%$ fetal bovine serum (Gibco/Thermo Fisher Scientific, Waltham, MA, USA) and $80 \mu \mathrm{g} / \mathrm{mL}$ gentamycin $\left(8 \times 10^{8} \mathrm{PFU} / \mathrm{mL}\right)$. Ka-gEI-memGFP-RV was injected into the vitreous body of the eye at the corneo-scleral junction or into the pituitary. Ka-VhsmemCherry- $A-R V$ or Ka-Vhs-CHR-memTomato- $A-R V$ was injected into the pituitary. Csáki and coworkers [24] confirmed the only retrograde or ante-retrograde transportation of our virus strains.

\subsection{Inoculation of the Pituitary Gland}

Under general anesthesia (chloral hydrate $35 \mathrm{mg} / 100 \mathrm{~g} \mathrm{bw}$ ), the animals were placed in a special stereotaxic instrument (commonly used for transauricular hypophysectomy). A hollow ear bar with a trocar inside was inserted into the right external auditory canal and pushed through the middle and inner ear toward the sella turcica. Through a glass tube that was inserted into the ear bar instead of the trocar, the animals received $2 \mu \mathrm{L}$ of one of the viruses into the pituitary gland. From the PP, the virus could have been transported only in a retrograde manner because, in this organ, neuronal cell bodies are not present. Nerve terminals picked up the virus and carried it toward the hypothalamus and along the sympathetic nerve fibers, which were also observed in the PP [25,26]. The anterior pituitary itself does not contain nerve endings coming from the hypothalamus. Only the brains of those animals were further processed, where the sellar dura and the median eminence (ME) were not injured (this fact was confirmed at autopsy). 


\subsection{Sympathectomy}

To prevent labeling through sympathetic fibers of the PP or sellar dura, we have also used cervical sympathectomized rats. Under general anesthesia, both superior cervical ganglion (SCG) were excised. The success of the surgery was proven by the appearance of ptosis, myosis, enophthalmos, and the lack of labeling in the IML of the corresponding spinal thoracic segment.

\subsection{Optic Nerve Cut}

Under general anesthesia, the animals were placed in a stereotaxic instrument in a nose-down position $(3.5 \mathrm{~mm})$. A piece of razor blade was fixed onto the holder. Its width was $2 \mathrm{~mm}$. The blade was lowered into the brain through a horizontal fissure drilled in the skull. When the blade reached the inner surface of the base of the skull, the right optic nerve was interrupted; then, the blade was removed. The coordinate was A10.4mm in front of the interaural line (IA), according to "The Rat Brain in Stereotaxic Coordinates" by Paxinos and Watson [27]. The rostral part of the hypothalamus, between A7mm and A11mm, was sectioned on the horizontal plain to check the location of the nerve injury.

\subsection{Experimental Groups}

Intact (non-sympathectomized) and sympathectomized animals were used. Labeling was sought in the hypothalamus and autonomic centers. The following groups were included in the experiments:

- Group 1: Ka-gEI-memGFP-RV injection into the pituitary of intact rats $(\mathrm{No}=2)$.

- Group 2: Ka-gEI-memGFP-RV injection into the pituitary of sympathectomized rats $(\mathrm{No}=2)$.

- Group 3: Ka-Vhs-memCherry-A-RV or Ka-Vhs-CHR-memTomato-A-RV injection into the pituitary of intact rats $(\mathrm{No}=2)$.

- Group 4: Ka-Vhs-memCherry-A-RV or Ka-Vhs-CHR-memTomato-A-RV injection into the pituitary of sympathectomized rats $(\mathrm{No}=2)$.

- Group 5: Ka-gEI-memGFP-RV injection into the vitreous body of the eye, inserting the needle of the Hamilton syringe at the corneoscleral junction at the temporal side of intact rats and Ka-Vhs-memCherry-A-RV or Ka-Vhs-CHR-memTomato- $A-R V$ injection into the pituitary ( $\mathrm{No}=7$; sympathetic, parasympathetic, and centrifugal visual fibers remain intact).

- Group 6: Ka-gEI-memGFP-RV injection into the vitreous body of the eye of sympathectomized rats and $K a-V h s-C H R$-memTomato- $A-R V$ injection into the pituitary (No = 7; parasympathetic and centrifugal visual fibers remain intact).

- Group 7: Ka-gEI-memGFP-RV injection into the vitreous body of eye of rats bearing the right optic nerve cut $(\mathrm{No}=3$; all autonomic fibers remain intact).

\subsection{Preparing Tissues for Investigations}

Three days after inoculation, the animals were anesthetized and perfused with $4 \%$ paraformaldehyde (PFA) in potassium phosphate buffer (KPB; 0.05Mol, pH7.2; Sigma, St. Louis, MO, USA). The brain, spinal cord, SCG, and ciliary ganglion (CilG) were removed, postfixed in PFA, then washed in KPB. The tissue blocks were treated with sucrose solution (Merck, Darmstadt, Germany) for cryoprotection and embedded in TissueTek (Sakura Finetek Europe B. V., Rijn, the Netherlands). Frozen sections were made with a cryotome (Thermo Shandon, Pittsburg, PA, USA). The slides were examined under a confocal fluorescence microscope (Radiance 2100 Rainbow Multiphoton Imaging System, Bio-Rad Laboratories, Hercules, CA, USA) using Zen 2012 software.

\subsection{Immunohistochemistry}

Sections of the hypothalamus, where double virus labeling was observed, were stained for OT immunoreactivity. First, the sections were washed in KPB and treated with $1 \%$ Triton X-100 (Reanal, Budapest, Hungary) for better penetration of the antibody. Then, the sections 
were treated with 1\% serum bovine albumin (Merck, Darmstadt, Germany) to diminish the background staining. After washing the slides three times in KPB OT-N, the monoclonal antibody, raised in mice and characterized by Ben-Barak and coworkers [28], was used in a dilution of 1:100. The sections were incubated in the antibody solution for $48 \mathrm{~h}$ at room temperature, and, after washing the slides three times in KPB, they were further incubated in goat anti-mouse biotinylated antibody for an hour (Vector, Burlingame, CA, USA). The final reaction product was visualized with aminomethylcoumarin acetate (AMCA; Jackson ImmunoResearch, Baltimore, MD, USA; 2-h incubation) to test the specificity of the OT-N antibody, the primary, and, in the other case, the biotinylated second antibody; alternatively, both were left out.

\subsection{Specificity of Labeling}

The specificity of the only retrograde or ante-retrograde spreading of our virus strains was tested in a previous paper [24]. Injection of the virus into blood resulted in no labeling anywhere in the central nervous system; this was also demonstrated in the same previous paper. By leaving the primary antibody out in the OT-N immunostaining, labeling was not observed. As a positive control, OT-N antibody characteristically stained neurons in the magnocellular PVN and SON.

\subsection{Evaluation of the Number of PVN and SON Neurons Labeled by Virus from the Eye}

From the hypothalamus of all experimental groups, starting at $7 \mathrm{~mm}$ in front of the IA, two parallel series of $20 \mu \mathrm{m}$ thick frontal sections were prepared. In every series, we had 15 sections (one from each $40 \mu \mathrm{m}$ thick tissue). The sections were mounted on gelatinized slidesin four to eight sections of the first series $K a-g E I-m e m G F P-R V$ labeled cells were counted, and then the double-virus-labeled cells were counted. As there was no difference in the data between male and female rats their data were analysed together. Data of intact and sympathectomized rats were compared. The data were subjected to one-way analysis of variance (ANOVA). Tukey's test was used as a post-test. Statistical significance was defined as $p<0.05$. The graphs were created by the GraphPad Prism 7 program. All values in the figures are expressed as mean \pm SEM.

\section{Results}

\subsection{Labeling Induced by Pituitary Inoculation}

Pituitary inoculation of intact and sympathectomized rats with Ka-gEI-memGFP-RV (Group 1 and 2) resulted in the labeling of the SON (Figure 1A) and PVN (Figure 1B) on both sides. In intact rats, labeling was observed mainly in the lateral part of the PVN (mPVN). As the pituitary gland and the sellar dura are innervated by sympathetic fibers; via these fibers, the virus is transported to the spinal autonomic center, the IML (T1-3 segments of the spinal cord; Figure 1C); then, from there, the virus might also reach some neurons in the PVN in a retrograde manner (Figure 1B). Sympathectomy did not considerably influence the labeling in the SON (Figure 1D) and PVN (Figure 1E); however, it did prevent labeling in the IML (Figure 1F).

Pituitary inoculation of intact and sympathectomized rats with Ka-Vhs-memCherryA-RV or Ka-Vhs-CHR-memTomato-A-RV (Groups 3 and 4) also induced labeling in the magnocellular system on both sides (Figure $1 \mathrm{G}, \mathrm{H}$ ). Labeling was not observed in the pPVN or any other parvocellular region of the hypothalamus (Figure 1I). The virus reached the second-order autonomic cell groups: the E-W nucleus (E-W; Figure 1J) and IML (Figure 1K). Pituitary inoculation of sympathectomized rats also resulted in the labeling of the SON (Figure 1L), mPVN (Figure 1M), and E-W nucleus (Figure 1N) but did not appear in the IML (Figure 1O). 

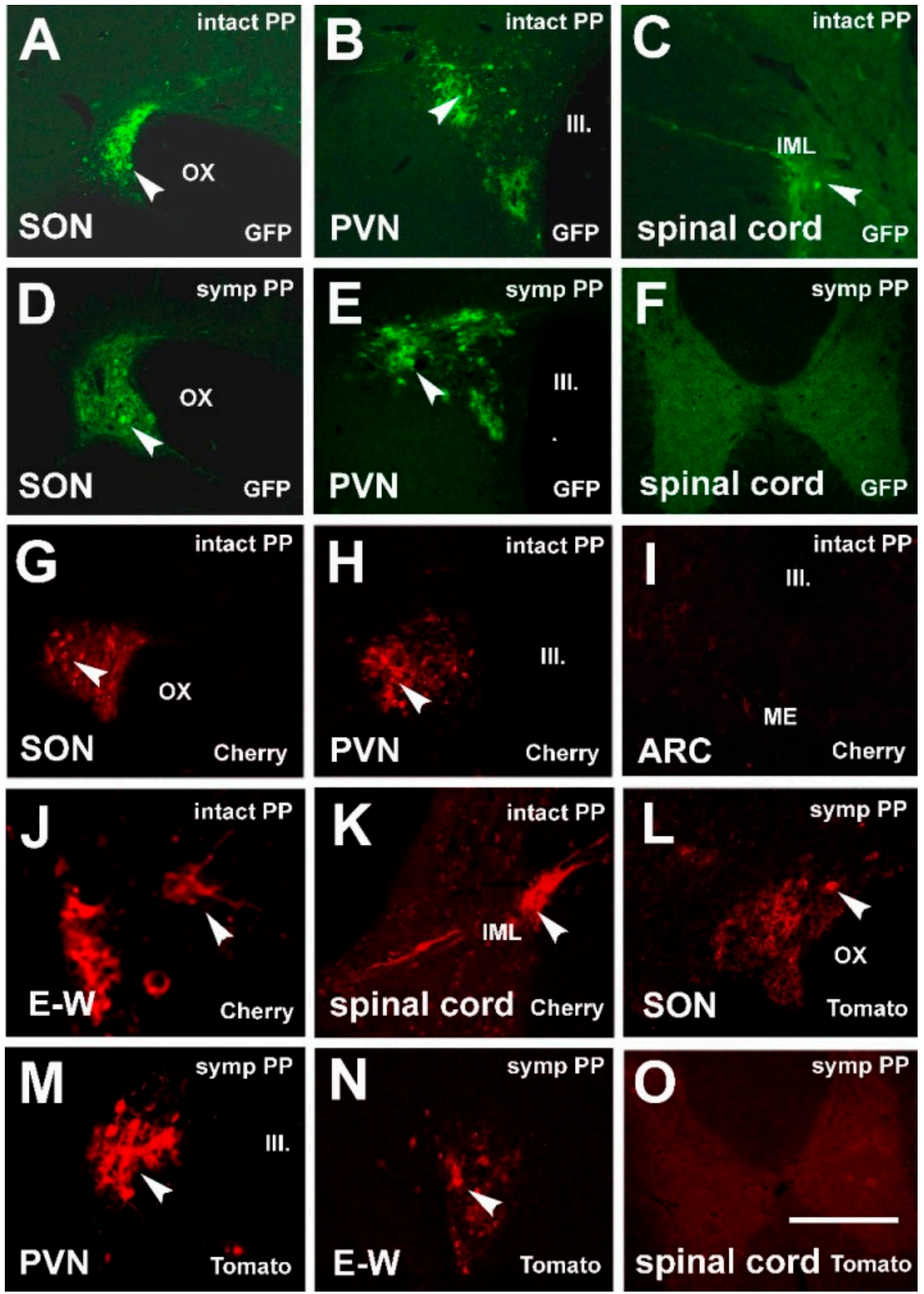

Figure 1. Fluorescent microscopic images demonstrating the retrograde spreading of virus strains after PP inoculation. (A-C) After inoculation of PP with Ka-gEI-memGFP-RV retrograde labeling in the magnocellular cell groups in the SON and PVN and labeling in the IML of the T2 segment of the spinal cord of an intact rat. (D,E) Retrograde labeling in the SON and PVN after PP inoculation with $K a-g E I-m e m G F P-R V$ of a sympathectomized rat. (F) Sympathectomy prevented labeling in the IML. $(\mathbf{G}, \mathbf{H})$ Retrograde labeling in the SON and PVN after inoculation of PP with Ka-Vhs-memCherry-A-RV. (I) Labeling is missing in the parvocellular ARC of the same animal. (J,K) Labeling appeared in preganglionic autonomic neurons in the E-W nucleus and IML after inoculation of PP with $\mathrm{Ka}-\mathrm{Vhs}$ memCherry- $A-R V$. (L-N) Labeling in the SON, PVN, and E-W nucleus after inoculation of PP with $K a-V h s-C H R$-memTomato- $A-R V$ of a sympathectomized rat. (O) Sympathectomy prevented labeling in the IML. Arrowheads show labeled neurons. Abbreviations: III. = third ventricle; ARC $=$ arcuate nucleus; IML = intermediolateral cell column; intact = no sympathectomy; Cherry = red fluorescence protein; $\mathrm{ME}=$ median eminence; $\mathrm{GFP}=$ green fluorescence protein; $\mathrm{OX}=$ optic chiasm; $\mathrm{PP}=$ posterior pituitary; $\mathrm{PVN}=$ paraventricular nucleus; $\mathrm{SON}=$ supraoptic nucleus; symp = sympathectomy; Tomato $=$ red fluorescence protein. Scale: $100 \mu \mathrm{m}$ in $(\mathbf{J}) ; 150 \mu \mathrm{m}$ in $(\mathbf{K}-\mathbf{M}), 200 \mu \mathrm{m}$ in $(\mathbf{A}-\mathbf{E}, \mathbf{G}-\mathbf{I}, \mathbf{N})$; $1000 \mu \mathrm{m}$ in $(\mathbf{F}, \mathbf{O})$. 


\subsection{Labeling, Focused on PVN, after Pituitary and Eye Inoculations (Groups 5 and 6)}

In intact rats (Group 5), Ka-gEI-memGFP-RV from the eye was transported in a retrograde manner to the postganglionic SCG (Figure 2A) and CilG (Figure 2B), then to the preganglionic neurons of IML (T2; Figure 2C) and E-W nucleus (Figure 2D). Finally, the virus reached the premotor neurons located in the hypothalamic PVN on both sides (Figure 2E).
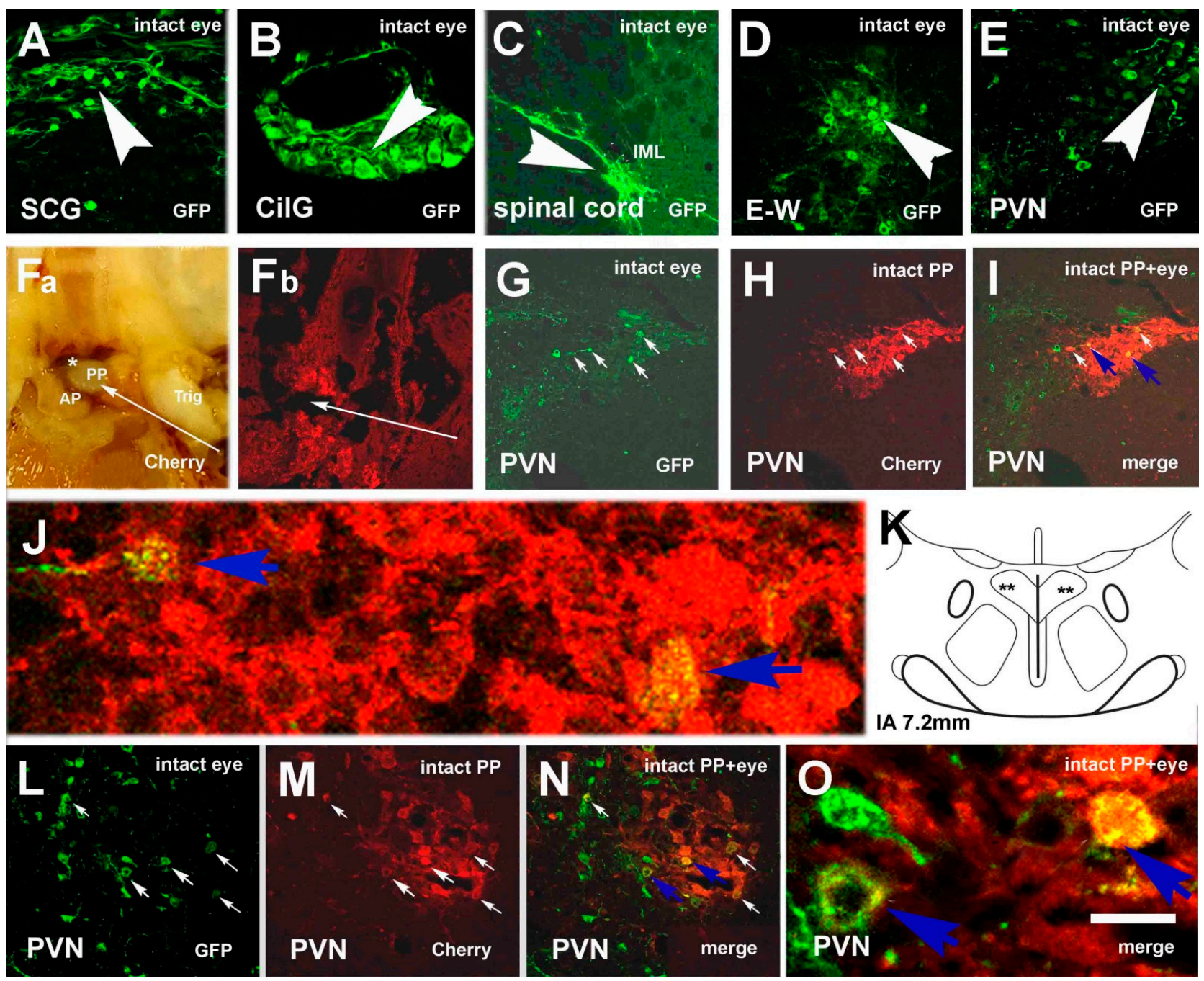

Figure 2. Microphotographs showing virus labeling in an intact rat after eye inoculation with Ka-gEI-mGFP-RV and pituitary inoculation with $K a-V h s-m C h e r r y-A-R V$. (A) Retrograde GFP labeling in the SCG, (B) in the CilG, (C) in the IML (T2), (D) in the E-W, and (E) in the PVN. (Fa) Inner surface of the base of the skull with the pituitary. Bleeding around the PP and under the sellar dura indicates the success of the inoculation. (Fb) Histological appearance of the pituitary injection site. (G-I) Double-virus-labeled neurons in the mPVN. (J) High power detail of (I). (K) Schematic illustration of the location of double-labeled neurons in the mPVN. (L-N) Another example of double-virus-labeled neurons in the mPVN. (O) High power detail of (N) Long slender arrows show the direction of pituitary inoculation; middle-size arrows show double-labeled neurons; small arrows in the same position show the same cells in (H-J) and (M-O); arrowheads show GFP-labeled neurons in (A-E). Blue arrows in $(\mathbf{I}, \mathbf{N})$ show the double-labeled cells, whose magnified images are seen in (J) and (O). Asterisk shows blood under the sellar dura. Abbreviations: AP = anterior pituitary; CilG = ciliary ganglion; $\mathrm{E}-\mathrm{W}=$ Edinger-Westfal nucleus; intact = no sympathectomy; Cherry = red fluorescence protein; GFP = green fluorescence protein; merge = merge image of Cherry and GFP labeling; $\mathrm{PP}=$ posterior pituitary; $\mathrm{PVN}=$ paraventricular nucleus; $\mathrm{SCG}=$ superior cervical ganglion; Trig = trigeminal nerve. Scale: $5000 \mu \mathrm{m}$ in (F); $1300 \mu \mathrm{m}$ in (G); $200 \mu \mathrm{m}$ in $(\mathrm{A}, \mathbf{C}, \mathbf{H}-\mathbf{J}) ; 150 \mu \mathrm{m}$ in (D,E,M-O); $100 \mu \mathrm{m}$ in (B); $15 \mu \mathrm{m}$ in (K,P). 
Figure 2Fa shows the macroscopic image of the pituitary injection site; Figure $2 \mathrm{Fb}$ demonstrates the histological appearance of the injection site. Through the anterior lobe, the glass capillary reached the PP, where the virus was taken up by the fibers and was transported through the pituitary stalk to the hypothalamus. In the $\mathrm{mPVN}$, double-labeled neurons were observed (Figure 2G-I). Figure 2J shows a highly magnified detail of Figure 2I. Figure 2K shows the hypothalamic level according to Paxinos and Watson's brain stereotaxic atlas, where double labeling is demonstrated in the mPVN. Figure 2L-N shows other double-labeled cells in the $\mathrm{mPVN}$; Figure $2 \mathrm{O}$ shows a highly magnified detail of Figure $2 \mathrm{~N}$.

In sympathectomized rats (Group 6) after eye inoculation with Ka-gEI-memGFP$R V$, labeling was observed in the optic nerve (Figure $3 \mathrm{~A}$ ) and the parasympathetic CilG (Figure 3B). The virus was further transported via the oculomotor nerve (Figure 3C) to the $\mathrm{E}-\mathrm{W}$ nucleus (Figure 3D); however, sympathectomy prevented the labeling in the sympathetic preganglionic neurons of the IML (Figure 3E). In the PVN (Figure 3F) and SON (Figure 3G), labeling was always found. The number of Ka-gEI-memGFP-RV-labeled cells in the PVN was lower in sympathectomized rats then in intact rats. The difference was statistically significant. However, in the SON, there was no difference in the number of GFP-labeled cells between the two groups (Figure 3H). In the SON, the number of GFP-labeled neurons was significantly lower than that in the PVN of either the intact or sympathectomized rats.

As was expected, the Ka-Vhs-CHR-memTomato- $A-R V$ virus signal was also observed in the SON (Figure $4 \mathrm{~A}$ ) and $\mathrm{mPVN}$ (Figure $4 \mathrm{~B}$ ). Labeling descended from the mPVN to the $\mathrm{E}-\mathrm{W}$ nucleus in an anterograde manner (Figure $4 \mathrm{C}$ ). As anterograde transport is slower than the retrograde, $\mathrm{Ka}-V h s-\mathrm{CHR}$-memTomato- $A-R V$ did not reach CilG until three days after the inoculation. Sympathectomy prevented the labeling in the IML (not shown). In the mPVN of sympathectomized rats, similar to those in intact rats, double-labeled neurons were also found. Figure 4 shows three examples of double labeling (Figure 4D-F,G-I,J-L).

3.3. Labeling Focused on the SON in the Case of the PP and Eye Inoculation of Intact, Sympathectomized Rats (Groups 5 and 6) and of Those Bearing Optic Nerve Cuts (Group 7)

The Ka-gEI-mem GFP-RV injected into the eye produced labeling in the SON in both intact (Figure 5A) and sympathectomized rats (Figure 5B); however, interruption of the optic nerve (Figure 5C,D) prevented SON labeling (Figure 5E) in spite of the fact that the inoculation of the eye was successful. In these latter animals, labeling appeared in the SCG, IML (Figure 5F), CilG, and E-W (Figure 5G). Finally, the labeling reached the PVN as well (Figure $5 \mathrm{H}$ ). In the case of simultaneous inoculation with Ka-Vhs-CHR-memTomato-A-RV, double labeling was observed in the SON of intact (Figure 5I-L,M) and sympathectomized rats (Figure $5 \mathrm{~N}-\mathrm{Q}, \mathrm{R}-\mathrm{U}$ ). 

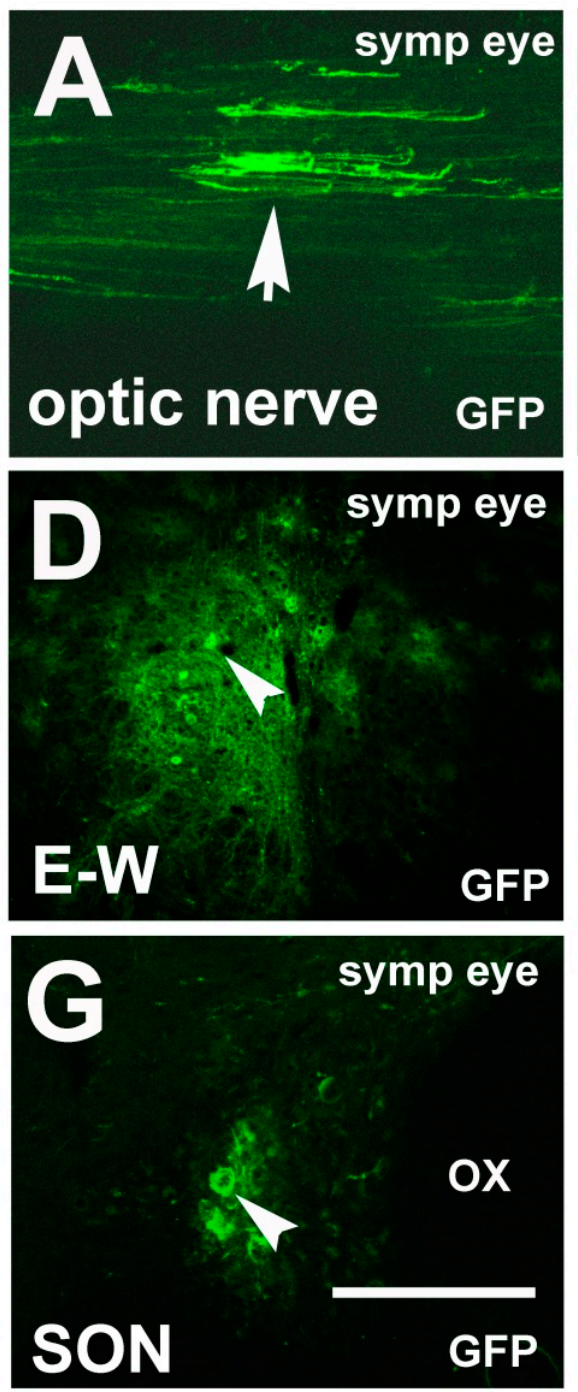
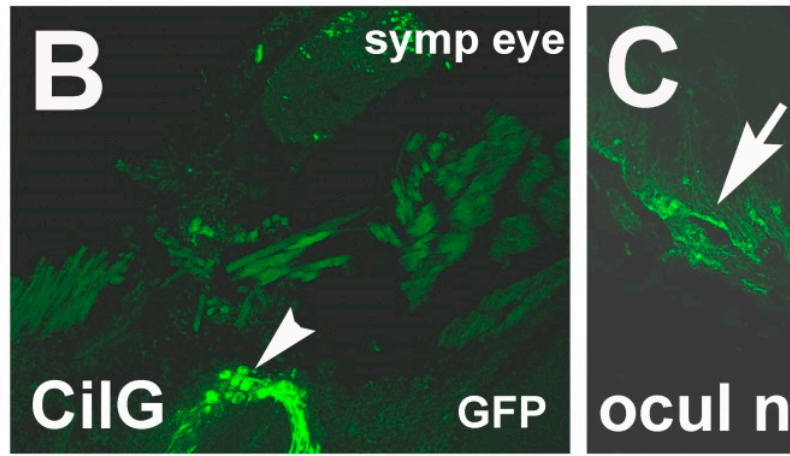

\section{symp eye}

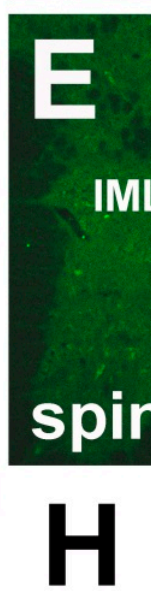

symp eye
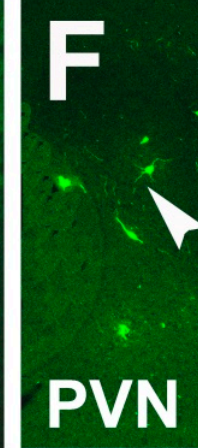

symp eye

ML

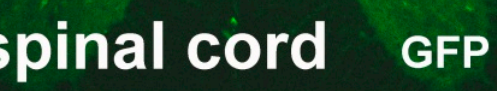

Virus labeled neurons in the PVN after inoculation of the right eye by Ka-gEI-memGFP-RV

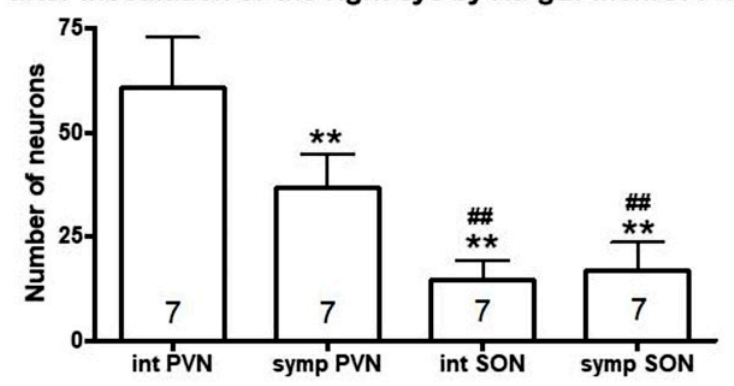

Figure 3. Microphotographs showing virus labeling after inoculation of the eye of a sympathectomized rat with $\mathrm{Ka}-\mathrm{g} E I-$ $m e m G F P-R V$. (A) Ka-gEI-memGFP-RV-labeled fibers in the optic nerve. (B) Ka-gEI-memGFP-RV-labeled fibers and neurons in the CilG. (C) Ka-gEI-memGFP-RV-labeled fibers in the oculomotor nerve. (D) Preganglionic parasympathetic neurons in the E-W nucleus. (E) Sympathectomy prevented Ka-gEI-mem GFP-RV-labeling in the IML. (F) Ka-gEI-memGFP-RV-labeling in the PVN. (G) Ka-gEI-memGFP-RV-labeling in the SON. (H) Bar chart showing the number of GFP-labeled cells in the PVN and SON of intact and sympathectomized rats. The number in the columns indicates the number of animals in the group. One-way ANOVA test and Tukey's post-test were used for the analysis of the results $\left(^{* *}=p<0.001\right.$ int PVN vs. symp PVN, int SON, symp SON, \#\# = $p<0.001$ int and symp PVN vs. int and symp SON). Arrows show labeled fibers; arrowheads show labeled cells. Abbreviations: CilG = ciliary ganglion; $\mathrm{E}-\mathrm{W}=$ Edinger-Westfal nucleus; $\mathrm{GFP}=$ green fluorescence protein; IML = intermediolateral cell column; ocul = oculomotorius; $\mathrm{OX}=$ optic chiasm; $\mathrm{PVN}=$ paraventricular nucleus; SON = supraoptic nucleus; symp = sympatectomized. Scale: $200 \mu \mathrm{m}$ in $(\mathbf{G}) ; 400 \mu \mathrm{m}$ in $(\mathbf{A}-\mathbf{D}, \mathbf{F}) ; 1000 \mu \mathrm{m}$ in $(\mathbf{E})$. 


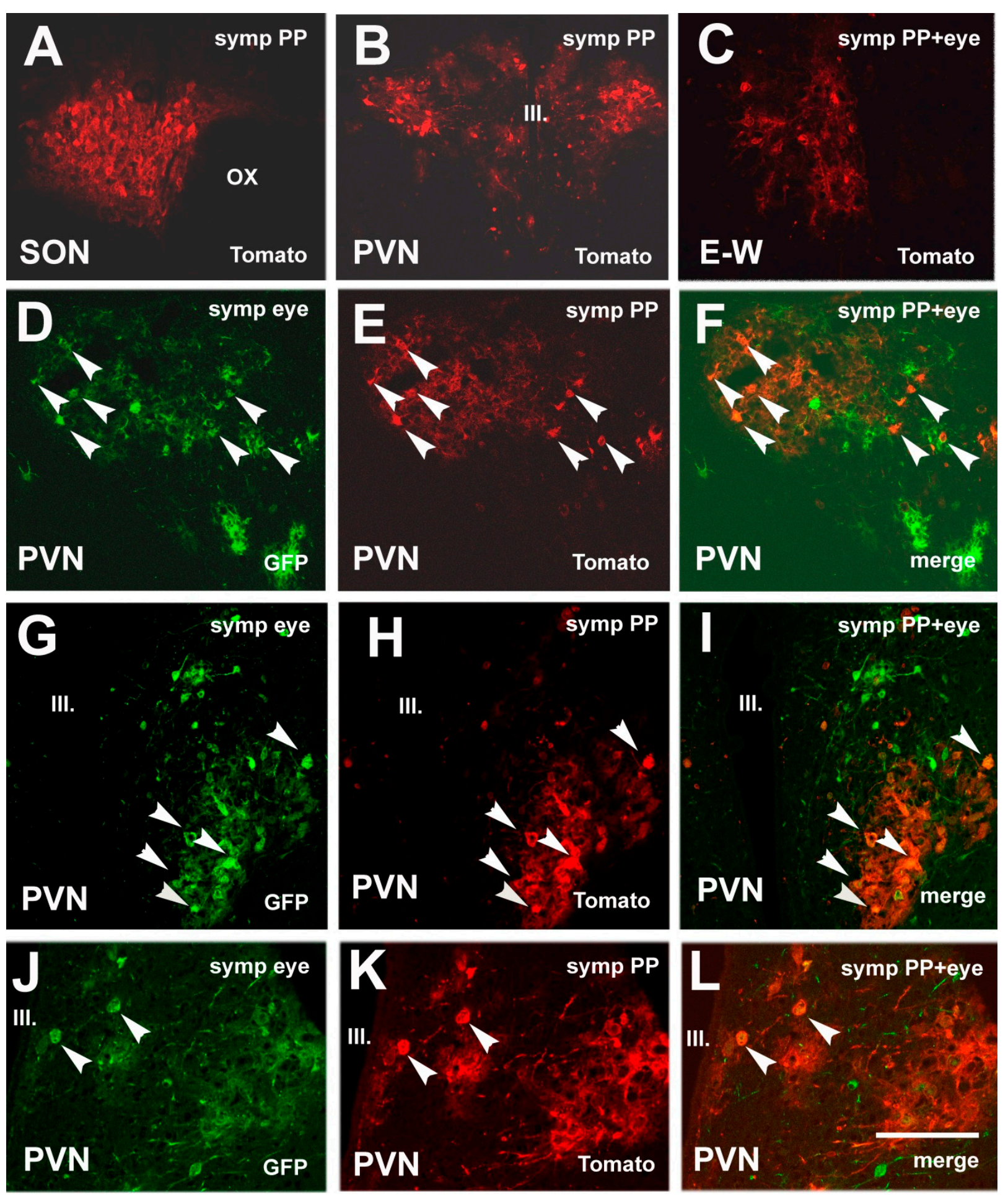

Figure 4. Microphotographs showing virus labeling after inoculation of the pituitary with Ka-Vhs-CHR-memTomato- $A$ - $R V$ and the eye with $K a-g E I-m e m G F P-R V$ in sympathectomized rats. (A) Ka-VhsCHR-memTomato- $A-R V$ labeling in the SON. (B) Ka-Vhs-CHR-memTomato- $A-R V$ labeling in the mPVN. (C) Ka-Vhs-CHR-memTomato- $A-R V$ labeling in the E-W. (D-L) Three examples of double-virus-labeled neurons in the mPVN. Arrowheads in the same position show the same cells. Abbreviations: III. = third ventricle; $\mathrm{E}-\mathrm{W}=$ Edinger-Westfal nucleus; GFP = green fluorescence protein; $\mathrm{PP}=$ posterior pituitary; PVN = paraventricular nucleus; SON = supraoptic nucleus; symp = sympathectomy. Scale: $200 \mu \mathrm{m}$ in $(\mathrm{J}-\mathbf{L})$, $400 \mu \mathrm{m}$ in (A,C-I); $800 \mu \mathrm{m}$ in (B). 

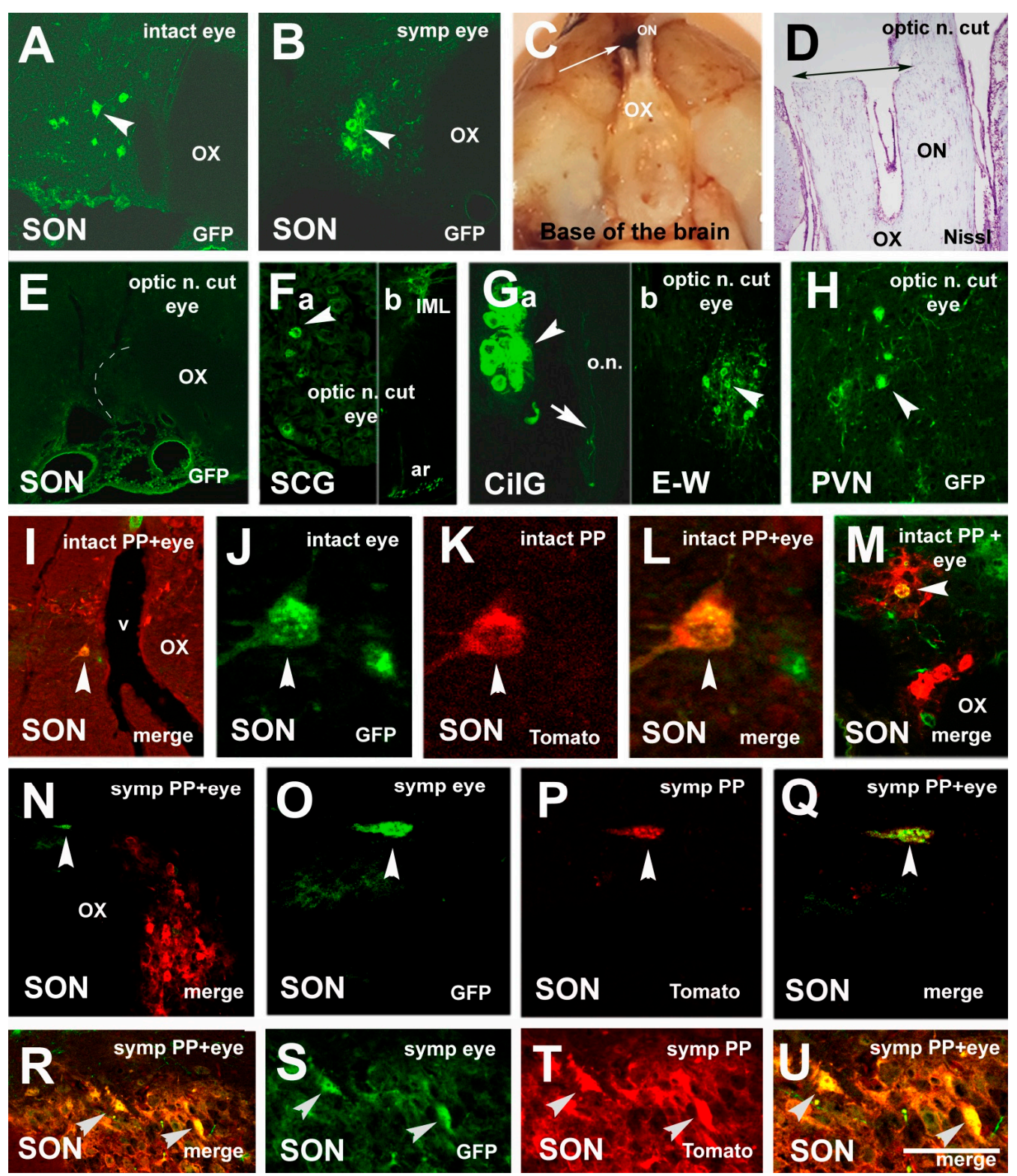

Figure 5. Microphotographs showing virus-labeled neurons in various groups. (A) Ka-gEI-memGFP-RV labeling in the SON of an intact rat. (B) Ka-gEI-memGFP-RV labeling in the SON of a sympathectomized rat. (C) Macroscopic image of the right optic nerve cut, as seen from the base of the brain. The caudal end of the right optic nerve is attached to the brain. The rostral stump of the nerve, in front of the cut, remained in the skull. (D) Histological appearance of the cut (Nissl staining). The right optic nerve is completely cut through; the left one is partially injured. (E) Optic nerve cut prevented Ka-gEI-memGFP-RV labeling in the SON. (F) Ka-gEI-memGFP-RV labeling in the SCG (a) and IML (b). (G) Ka-gEI-memGFP-RV labeling in the CilG (a) and E-W nucleus (b). In the rostral stump of the right optic nerve, a very delicate Ka-gEI- $m G F P-R V$-labeled fiber can be seen (a). It is shown with an arrow. (H) Ka-gEI-memGFP-RV-labeling in the PVN. (I) A merged image of double $K a-V h s-C H R$-memTomato- $A-R V$ and Ka-gEI-mem GFP-RV-labeling in the SON of an intact rat. (J-L) Highly magnified image of a double-labeled cell. (M) Another example of double-labeling in the SON of an intact rat. (N) A merged image of double Ka-Vhs-CHR-memTomato-A-RV and Ka-gEI-memGFP-RV labeling in the SON of a sympathectomized rat. (O-Q) High magnified images of a double-labeled cell. (R) Another example of double-labeling in the SON of a sympathetomized rat. (S-U) High magnified image of double-labeled cells. Arrowheads in the same position indicate the same cells in $(\mathbf{I}-\mathbf{L}, \mathbf{N}-\mathbf{Q}, \mathbf{R}-\mathbf{U})$. Slender arrows show the place of the right optic nerve cut. Abbreviations: ar = anterior rootlet; GFP = green fluorescence protein; $\mathrm{n}$. = nerve; o.n. = optic nerve; $\mathrm{ON}=$ optic nerve; $\mathrm{OT}=$ optic tract; $\mathrm{OX}=$ optic chiasm; $\mathrm{PP}=$ posterior pituitary; $\mathrm{PVN}=$ paraventricular nucleus; $\mathrm{SON}=$ supraoptic nucleus; Tomato $=$ red fluorescence protein; $\mathrm{v}=$ vessel. Scale: $15 \mu \mathrm{m}$ in (J-L), $50 \mu \mathrm{m}$ in (O-Q,S-U); $100 \mu \mathrm{m}$ in (Ga,M); $200 \mu \mathrm{m}$ in (A,B,E,F,Gb,H,I,N,R); $1000 \mu \mathrm{m}$ in (D); $5000 \mu \mathrm{m}$ in (C). 
The number of double-labeled neurons was always lower than the number of $K a-g E I-$ memGFP-RV-labeled neurons (Figure 6). About one-quarter of the GFP-labeled cells were projected to the PP as well.

\section{Ratio of single and double labeled neurons in the PVN and SON}

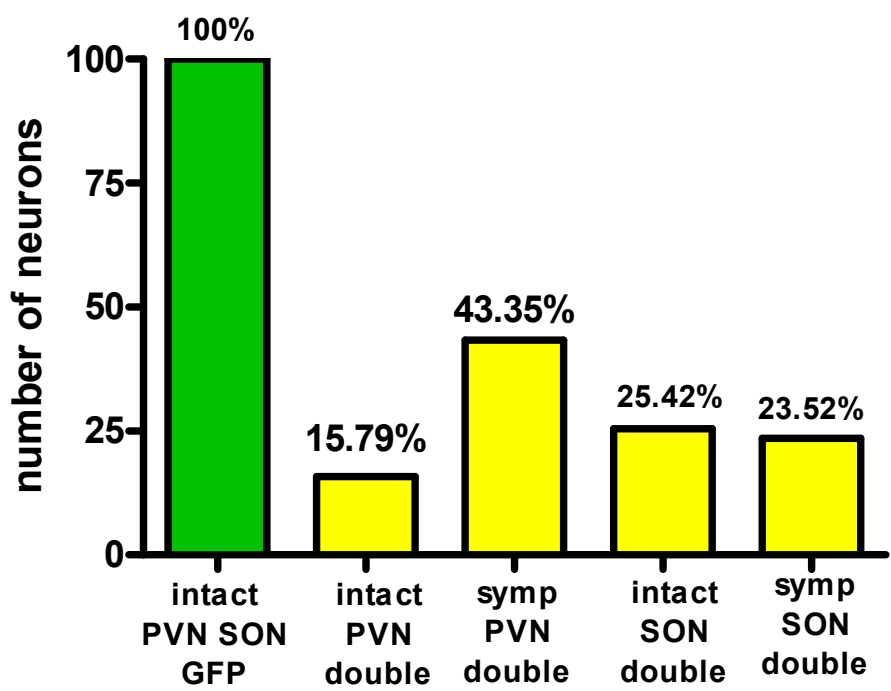

Figure 6. Bar chart showing the ratio of double-labeled cells in the PVN and SON of intact and sympathectomized rats compared to the number of single GFP-labeled neurons.

\subsection{Chemical Characterization of Double-Labeled Neurons in the mPVN and SON}

Injection of $K a-g E I-m e m G F P-R V$ into the eye and $K a$-Vhs-memCherry- $A-R V$ into the PP of intact rats (Group 6) resulted in double-virus-labeled cells in the mPVN and SON. Immunostaining revealed that some double-virus-labeled neurons also showed OT-N immunoreactivity in both nuclei. Figure 7A-H show triple labeling in the PVN and SON of intact rats. Figure 7I-P show triple-labeled neurons in the PVN and SON of sympathectomized rats. The number of triple-labeled neurons is much lower than the number of double-labeled neurons. 

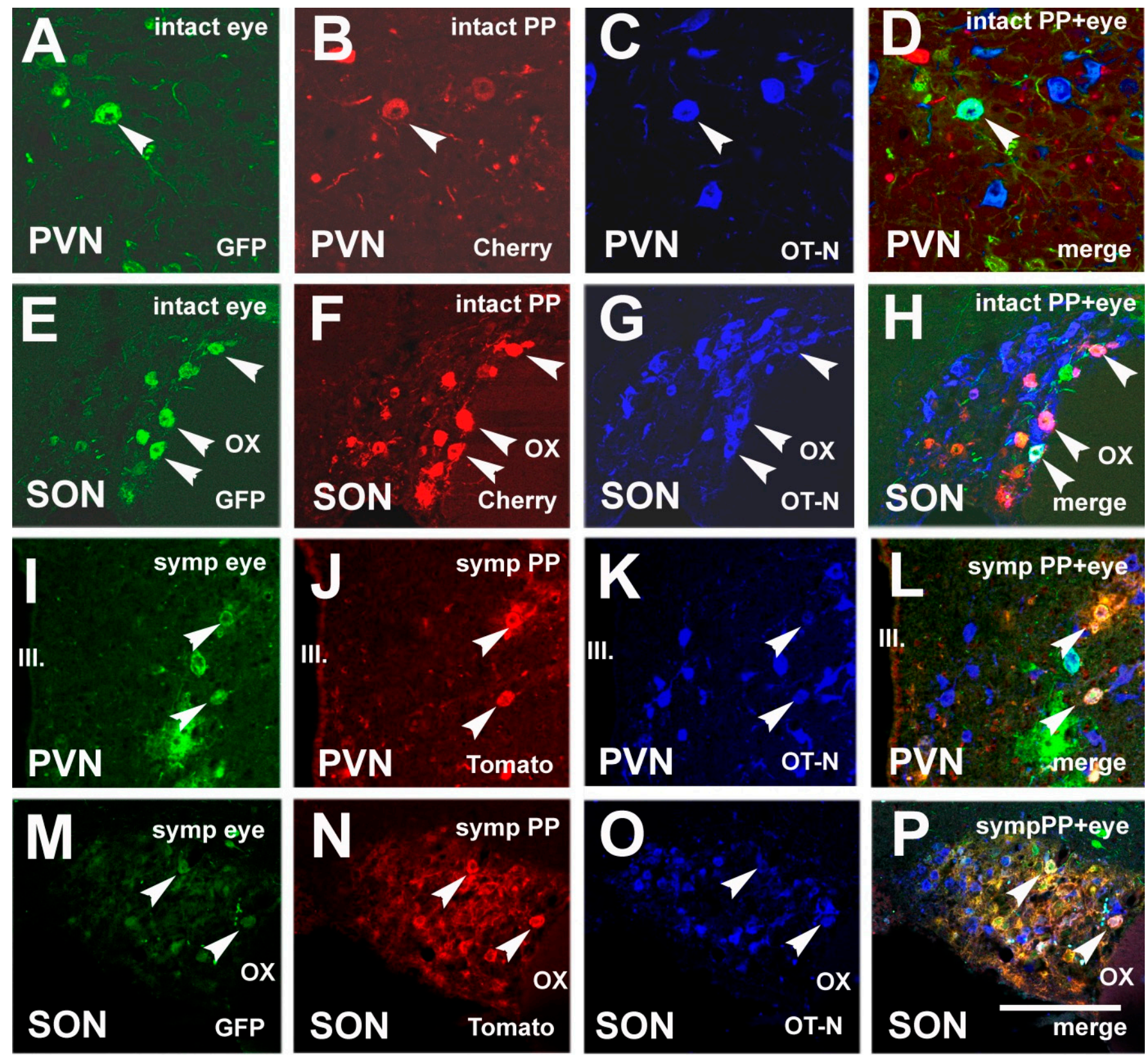

Figure 7. Microphotographs showing OT-N immunoreactivity in double-virus-labeled neurons in the PVN and SON. (A) Ka-gEI-mem GFP-RV-labeling in the PVN of an intact rat. (B) Ka-Vhs-memCherry-A-RV-labeling in the PVN of the same section of an intact rat. (C) OT-N immunostaining in the PVN of the same section of an intact rat. (D) Triple-labeled neuron in a confocal merge image of the PVN. (E) Ka-gEI-memGFP-RV labeling in the SON of an intact rat. (F) Ka-Vhs-memCherry-A$R V$-labeling in the SON of the same section of an intact rat. (G) OT-N immunostaining in the SON of the same section of an intact rat. (H) Triple-labeled neurons in a confocal merge image of the SON. (I) Ka-gEI-memGFP-RV labeling in the PVN of a sympathectomized rat. (J) Ka-Vhs-CHR-memTomato- $A-R V$ labeling in the PVN of the same section of a sympathectomized rat. (K) OT-N immunostaining in the PVN of the same section of a sympathetomized rat. (L) Triple-labeled neuron in a confocal merge image of the PVN. (M) Ka-gEI-memGFP-RV-labeling in the SON of a sympathectomized rat. (N) Ka-Vhs$C H R$-memTomato- $A-R V$-labeling in the $\mathrm{SON}$ of the same section of a sympathectomized rat. (O) OT-N immunostaining in the SON of the same section of a sympathectomized rat. (P) Triple-labeled neuron in a confocal merge image of the SON. Arrowheads indicate the same cells in the same position in (A-D,E-H,I-L,M-P). Abbreviations: GFP = green fluorescence protein; OT-N = oxytocin neurophysin; $\mathrm{OX}=$ optic chiasm; $\mathrm{PP}=$ posterior pituitary; $\mathrm{PVN}$ = paraventricular nucleus; $\mathrm{SON}=$ supraoptic nucleus, Tomato and Cherry = red fluorescence proteins. Scale: $150 \mu \mathrm{m}$ in (A-D) and $200 \mu \mathrm{m}$ in (E-P). 


\section{Discussion}

It is generally accepted that PPVN neurons project to the IML of the spinal cord. These neurons are collectively termed SPANs. SPAN cell bodies are found most densely in the mediocellular [8,9] or, according to Pyner and Coote [10], in the mid-rostral subdivision of the PVN. Their function is a subject of debate. Most likely, SPANs may be involved in physiological stress responses, cardiovascular control, glucose regulation, thermoregulation, and circadian rhythms [29]. The OT neurons are mainly located in the mPVN. Some pPVN neurons also show OT immunoreactivity. Althammer and Grinevich [17] have supposed that the parvocellular OT neurons do not project to the PP; however, through multiple axon collaterals, these neurons project to the hindbrain and spinal cord regions, mainly to the posterior horn, where they modulate pain perception [30]. The role of OT in social behavior, cognition, and autonomic cardiac control in psychiatric disorders of social dysfunction has been thoroughly studied, and its impact in these conditions is generally accepted [31].

In our previous experiments, we have found virus-labeled neurons not only in the pPVN but in the $\mathrm{mPVN}$ after injection of a retrograde traveling virus into some peripheral organs such as the mammary gland [13], lower gingiva, or lower lip of rats [14]. There is also considerable evidence that axons of the PVN neurons branch and innervate neurons that are located in at least two different places $[15,16]$. It was also demonstrated that oxytocinergic $\mathrm{mPVN}$ neurons also innervated neurons in the central amygdala, where the local release of OT mediated the unfreezing response via GABAergic interneurons [17]. In our material, only a few double-virus-labeled cells showed OT-N immunoreactivity. This fact raises the possibility that these cells operate with neuropeptides or neurotransmitters other than OT. The question arises as to what the role of the small number of oxytocinerg $\mathrm{mPVN}$ neurons that project to the E-W nucleus and the IML. Morphologically, a bidirectional connection exists between the PVN and the E-W nucleus. Dos Santo and coworkers [32] injected BDA into the E-W nucleus; they have found labeling in the PVN. In our experiment, $\mathrm{Ka}-\mathrm{Vhs}$ $C H R$-memTomato- $A-R V$, expressing red fluorescence protein, from the PVN descended to the E-W nucleus in an anterograde manner. As we have found double-labeled oxytocinerg neurons in sympathectomized rats, we suppose that this labeling has to belong to the centrifugal visual or premotor parasympathetic neurons, which may project to the retina or the E-W nucleus. Buijs [33] described oxytocinergic fibers in the E-W nucleus. This observation supports our hypothesis.

Our present experiment provides further insight into the anatomy of the premotor autonomic innervation of the eye. We have shown that there are neurons not only in pPVN but also the mPVN, the axons of which branch and send collaterals into the PP and simultaneously to autonomic neurons located in the E-W and IML of the spinal cord. It means that the same magnocellular neurons may function as neuroendocrine cells and sympathetic and parasympathetic premotor neurons. We named these neurons autonomic premotor PPPNs.

In the PVN and SON, we would have liked to know how many percent of virus-labeled neurons received a virus from the sympathetic nervous system (IML) after eye inoculation. When we injected the virus into the vitreous body of the eye, not only the retinal ganglion cells but the sympathetic and parasympathetic fibers innervating the pupillary and ciliary muscles also picked up and transported the virus. SCG and CilG were always labeled in Group 5. From here, the virus, in a retrograde manner, was transported to the IML and the E-W nucleus. It is also clear that significantly more signals hit the eye from the PVN than from the SON. The chart (Figure 6) shows that about $45 \%$ of PVN fibers descend to parasympathetic centers or the centrifugal visual fibers, and this difference is statistically significant (Figure $3 \mathrm{H}$ ). In the SON, there is no difference between the sympathectomized and non-sympathectomized groups. Significantly more PVN neurons are labeled from the eye than SON neurons. This difference is due to the fact that the SON does not directly connect with the autonomic nervous system.

In another rodent (prairy vole), Eliava and coworkers [34], using tract-tracing and electrophysiological methods, identified pPVN OT neurons that project to the spinal cord 
and simultaneously to the PP or to other mPVN OT or SON OT neurons; in turn, these OT neurons project to the PP. They also identified pPVN OT neurons with axon collateral to the $\mathrm{PP}$ and another to the spinal dorsal horn. These identified connections, existing between the PVN, PP, and the dorsal horn, are involved in pain perception. It is not known whether the above observation would be true for rat ciliary autonomic centers as well as for the PVN, PP, E-W nucleus, and T2 IML. Not oxytocin fibers but oxytocin receptors were also demonstrated in another rodent. Wrobel and coworkers [35], using OT-receptor-reporter mice, in which a fluorescent protein (Venus) was expressed, found OT receptors in about $5 \%$ of preganglionic IML neurons.

After eye inoculation, we have found viral-labeled neurons in the SON. This observation correlates well with our previous data. After injection of the vitreous body with BDA, retrograde-labeled neuronal cell bodies appeared in the SON and PVN. It was concluded that the labeled neurons sent centrifugal visual fibers to the retina [6]. There are no data in the literature that indicate that $\mathrm{SON}$ does directly send premotor fibers to the autonomic centers. We have never observed labeling in this nucleus after the gingiva, lip [14], and adrenal inoculations (unpublished data). The finding that an interruption of the right optic nerve (the retrograde virus was injected into the right eye) prevented the labeling in the SON, but not in the PVN, strongly supports the above-mentioned observation. In these animals, the tracer, injected into the eye, could reach the PVN through the CilG and E-W or through SCG and IML, but not through the optic nerve. In our sympathectomized rats, the persisting retrograde fiber labeling in the optic nerve also suggests that these fibers belong to the centrifugal visual system. These phenomena also support our hypothesis that the virus-labeled neurons in the SON are the cells of origin of the centrifugal visual fibers. The labeled neurons in the PVN of intact animals may belong to sympathetic and parasympathetic premotor systems, and these cells may be the origin of the centrifugal visual system.

There is information on the roles of OT and AVP in the control of the eye autonomic nervous system. It is well established the PVN sends information to the E-W nucleus and the corresponding IML; the E-W nucleus innervates the CilG; the IML innervates the SCG. In turn, the CilG and SCG are responsible for pupil mimicry and lens accommodation and influence choroidal blood flow. A research group [36] observed that when two people talk to one another at close range, they tend to trust one another more if their pupils are dilated or less if there is constriction. In males, the application of intranasal OT enhanced trust; in females, OT depressed trust. In rabbits, intravitreal administration of a very low dose $\left(10^{-10} \mathrm{M}\right)$ of AVP induced pupillary constriction [37].

The role of OT in the retina was investigated by Halbach and coworkers [21]. They have described that OT is present in the cone photoreceptor extracellular matrix and the OT receptor is present in the adjacent retinal pigment epithelium. OT is a paracrine signaling molecule and induces an increase in the retinal pigment epithelium [Ca2+]i level via the activation of the OT receptor. These results do not explain without doubt the origin of OT in the retina. We have found several OT immunoreactive double-labeled cells in the SON. These cells may be the source of OT in the retina. Althammer and coworkers [19] claimed that only a few molecules might have functional consequences because the OT receptors exhibit a high affinity for their ligand. Another nonapeptide, AVP, was also found in the retina. Its level is very low, but a special technique, using AVP-eGFP transgenic rats, was able to demonstrate AVP immunoreactive cells in the ganglion cell layer and the inner nuclear layer. AVP mRNA in these cells was also shown. V1a and V1b receptors were also found in the retina. The authors concluded that AVP-synthesizing and AVP-receiving mechanisms can operate in a paracrine manner [23]. Figure 8 illustrates our hypothesis. 


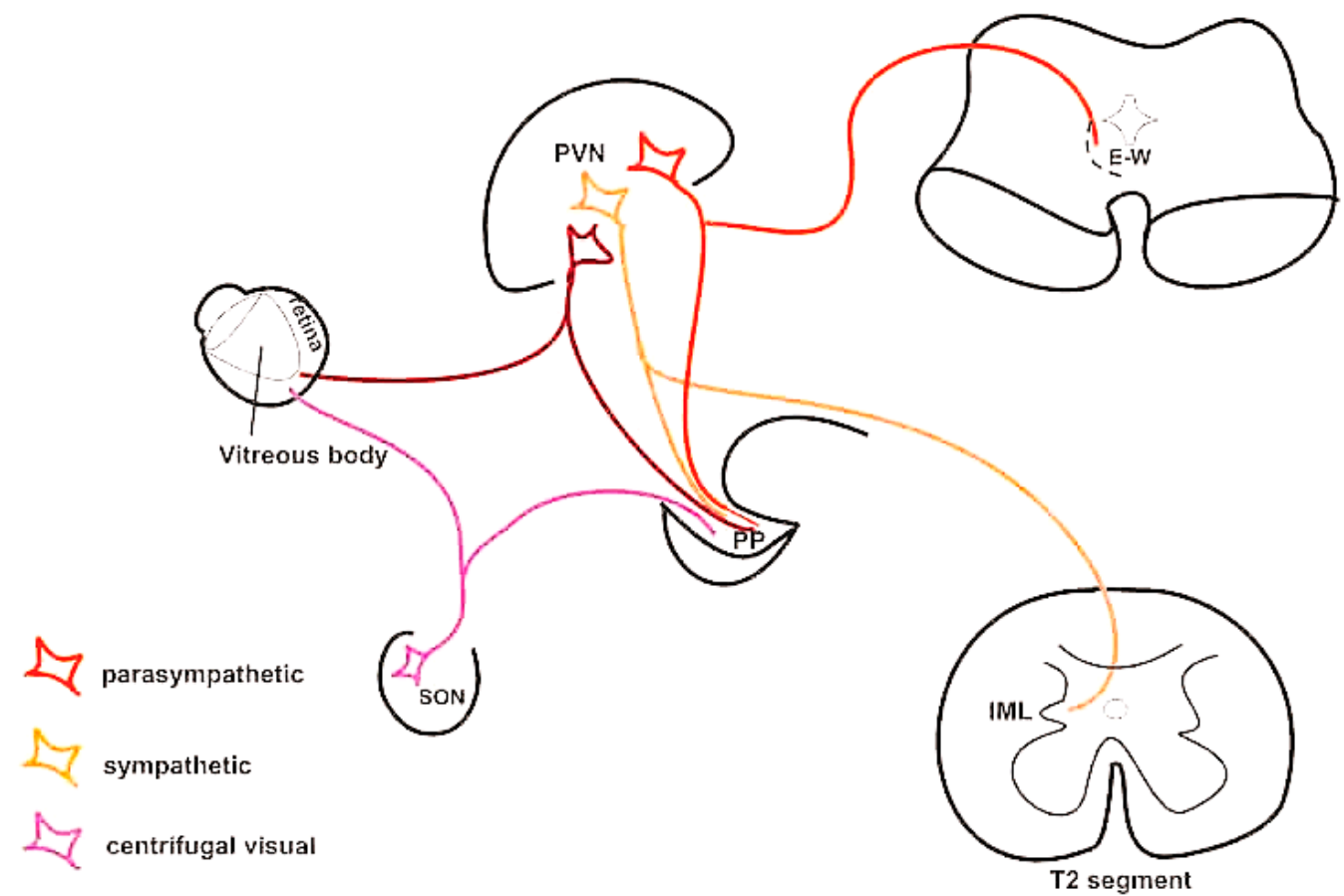

Figure 8. Schematic illustration of our hypothesis. Abbreviations: E-W = Edinger-Westphal nucleus; IML = intermediolateral cell column of the spinal cord; $\mathrm{PP}=$ posterior pituitary; $\mathrm{PVN}=$ paraventricular nucleus; $\mathrm{SON}$ = supraoptic nucleus; $\mathrm{T} 2$ = second thoracic segment of the spinal cord.

\section{Conclusions}

(1) The same mPVN neurons that project to the PP may be the cell of origin of centrifugal visual fibers or autonomic premotor neurons. (2) The double-labeled mPVN neurons are not only sympathetic but parasympathetic as well because similar observations were also made in intact and sympathectomized rats. (3) In the SON, each double-labeled neuron is the cell of origin of centrifugal visual fiber. (4) Some of the double-labeled neurons in the $\mathrm{mPVN}$ and $\mathrm{SON}$ are oxytocinergic.

Author Contributions: Conceptualization: K.K. and Á.C. Methodology: Á.C., K.K., D.T. and Z.B. Formal analysis and investigation: K.K. and Á.C. Writing and review: K.K., Á.C. and Z.E.T. All authors have read and agreed to the published version of the manuscript.

Funding: This work was supported by the Department of Anatomy, Histology and Embryology, Semmelweis University, and a grant from the National Research, Development and Innovation Office (OTKA K128247) to Z.B.

Institutional Review Board Statement: The study was conducted according to the guidelines of the Declaration of Helsinki, and approved by the Semmelweis University's Institutional Animal Care and Use Committee (Permission\# 22.1/1158/3/2010 and date of approval: 22.01.2010.).

Informed Consent Statement: Not applicable.

Data Availability Statement: Data of the bar charts are not available at this time.

Acknowledgments: We are very grateful to Anna Takács for her excellent technical assistance. This work was supported by the Department of Anatomy, Histology and Embryology, Semmelweis University, Budapest, Hungary, and a grant from the National Research, Development and Innovation Office (OTKA K128247) to Z.B.

Conflicts of Interest: The authors declare no conflict of interest. 


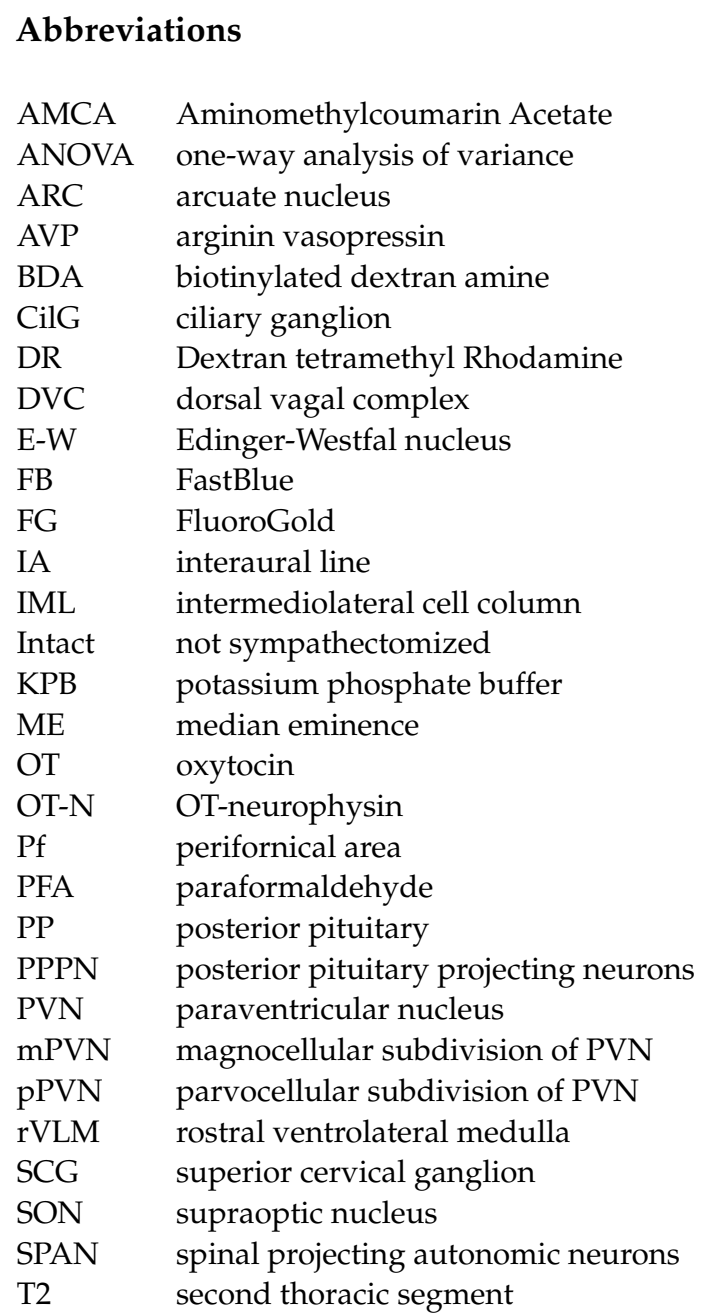

\section{References}

1. Wright, C.B.; Redmond, T.M.; Nickerson, J.M. A History of the Classical Visual Cycle. Prog. Mol. Biol. Transl. Sci. 2015, 134, 433-448. [CrossRef] [PubMed]

2. Moore, R.Y.; Lenn, N.J. A retinohypothalamic projection in the rat. J. Comp. Neurol. 1972, 146, 1-14. [CrossRef] [PubMed]

3. Hendrickson, A.E.; Wagoner, N.; Cowan, W.M. An autoradiographic and electron microscopic study of retino-hypothalamic connections. Z. Zellforsch. Mikrosk. Anat. 1972, 135, 1-26. [CrossRef] [PubMed]

4. $\quad$ Ramon y Cajal, S. La retine des Vertebres. Cellule 1893, 9, 17-257.

5. Repérant, J.; Miceli, D.; Vesselkin, N.P.; Molotchnikoff, S. The centrifugal visual system of vertebrates: A century-old search reviewed. Int. Rev. Cytol. 1989, 118, 115-171. [CrossRef]

6. Vereczki, V.; Köves, K.; Csáki, Á.; Grosz, K.; Hoffman, G.E.; Fiskum, G. Distribution of hypothalamic, hippocampal and other limbic peptidergic neuronal cell bodies giving rise to retinopetal fibers: Anterograde and retrograde tracing and neuropeptide immunohistochemical studies. Neuroscience 2006, 140, 1089-1100. [CrossRef]

7. Hosoya, Y.; Matsushita, M. Identification and distribution of the spinal and hypophyseal projection neurons in the paraventricular nucleus of the rat. A light and electron microscopic study with the horseradish peroxidase method. Exp. Brain. Res. 1979, 35, 315-331. [CrossRef]

8. Swanson, L.W.; Kuypers, H.G. The paraventricular nucleus of the hypothalamus: Cytoarchitectonic subdivisions and organization of projections to the pituitary, dorsal vagal complex, and spinal cord as demonstrated by retrograde fluorescence double-labeling methods. J. Comp. Neurol. 1980, 194, 555-570. [CrossRef]

9. Hallbeck, M.; Larhammar, D.; Blomqvist, A. Neuropeptide expression in rat paraventricular hypothalamic neurons that project to the spinal cord. J. Comp. Neurol. 2001, 433, 222-238. [CrossRef]

10. Pyner, S.; Coote, J.H. Identification of branching paraventricular neurons of the hypothalamus that project to the rostroventrolateral medulla and spinal cord. Neuroscience 2000, 100, 549-556. [CrossRef]

11. Maejima, Y.; Kumamoto, K.; Takenoshita, S.; Shimomura, K. Projections from a single NUCB2/nesfatin-1 neuron in the paraventricular nucleus to different brain regions involved in feeding. Brain Struct. Funct. 2016, 221, 4723-4731. [CrossRef] 
12. Strack, A.M.; Sawyer, W.B.; Hughes, J.H.; Platt, K.B.; Loewy, A.D. A general pattern of CNS innervation of the sympathetic outflow demonstrated by transneuronal pseudorabies viral infections. Brain Res. 1989, 491, 156-162. [CrossRef]

13. Köves, K.; Györgyi, Z.; Szabó, F.K.; Boldogkői, Z. Characterization of the autonomic innervation of mammary gland in lactating rats studied by retrograde transynaptic virus labeling and immunohistochemistry. Acta Physiol. Hung. 2012, 99, 148-158. [CrossRef]

14. Szabó, E.; Boldogkői, Z.; Csáki, Á.; Tóth, Z.; Köves, K. Autonomic neuronal chains innervating lower incisive gingiva and lip in rat. Trans-synaptic tracing study. Auton. Neurosci. Basic Clin. 2015, 190, 10-19. [CrossRef]

15. Gerendai, I.; Tóth, I.E.; Boldogkői, Z.; Halász, B. Recent findings on the organization of central nervous system structures involved in the innervation of endocrine glands and other organs; observations obtained by the transneuronal viral double-labeling technique. Endocrine 2009, 36, 179-188, Review. [CrossRef]

16. Hettigoda, N.S.; Fong, A.Y.; Badoer, E.; McKinley, M.J.; Oldfield, B.J.; Allen, A.M. Identification of CNS neurons with polysynaptic connections to both the sympathetic and parasympathetic innervation of the submandibular gland. Brain Struct. Funct. 2015, 220, 2103-2120. [CrossRef]

17. Althammer, F.; Grinevich, V. Diversity of oxytocin neurons: Beyond magno- and parvocellular cell types? J. Neuroendocrinol. 2017, 29, e12549. [CrossRef]

18. Knobloch, H.S.; Charlet, A.; Hoffmann, L.C.; Eliava, M.; Khrulev, S.; Cetin, A.H.; Osten, P.; Schwarz, M.K.; Seeburg, P.H.; Stoop, R.; et al. Evoked axonal oxytocin release in the central amygdala attenuates fear response. Neuron 2012, 73, 553-566. [CrossRef]

19. Althammer, F.; Jirikowski, G.; Grinevich, V. The oxytocin system of mice and men-Similarities and discrepancies of oxytocinergic modulation in rodents and primates. Peptides 2018, 109, 1-8. [CrossRef]

20. Freeman, S.M.; Young, L.J. Comparative perspectives on oxytocin and vasopressin receptor research in rodents and primates: Translational implications. J. Neuroendocrinol. 2016, 28. [CrossRef]

21. Halbach, P.; De-Ann, M.P.; York, N.; Asuma, M.P.; Chiu, M.A.; Luo, W.; Tokarz, S.; Bird, I.M.; Pattnaik, B.R. Oxytocin and Function in the Posterior Retina: A Novel Signaling Pathway. Investig. Ophthalmol. Vis. Sci. 2015, 6, 751-760. [CrossRef]

22. York, N.; Halbach, P.; Chiu, M.A.; Bird, I.M.; De-Ann, M.P.; Pattnaik, B.R. (OXT)-stimulated inhibition of Kir7. 1 activity is through PIP2-dependent Ca2+ response of the oxytocin receptor in the retinal pigment epithelium in vitro. Cell Signal. 2017, 37, 93-102. [CrossRef]

23. Moritoh, S.; Sato, K.; Okada, Y.; Koizumi, A. Endogenous arginine vasopressin-positive retinal cells in arginine vasopressin-eGFP transgenic rats identified by immunohistochemistry and reverse transcriptase-polymerase chain reaction. Mol. Vis. 2011, 17, 3254-3261.

24. Csáki, Á.; Vígh, B.; Boldogkői, Z.; Szél, Á.; Köves, K. Is a neuronal chain between the pineal body and the retina in rats and hamsters? Transneuronal tracing studies. Neurosci. Lett. 2015, 588, 1-6. [CrossRef]

25. Dandy, W.E. The nerve supply to the pituitary body. Am. J. Anat. 1913, 15, 333-343. [CrossRef]

26. Saavedra, J.M. Central and peripheral catecholamine innervation of the rat intermediate and posterior pituitary lobes. Neuroendocrinology 1985, 40, 281-284. [CrossRef]

27. Paxinos, G.; Watson, C. The Rat Brain in Stereotaxic Coordinates; Academic Press Inc.: San Diego, CA, USA, 1986.

28. Ben-Barak, J.Y.; Russel, T.; Whitnall, M.H.; Ozato, K.; Gainer, H. Neurophysin in the hypothalamo-hypophysial system, I. Production and characterization of monoclonal antibodies. J. Neurosci. 1985, 5, 81-97. [CrossRef]

29. Nunn, N.; Womack, M.; Dart, C.; Barrett-Jolley, R. Function and pharmacology of spinally-projecting sympathetic pre-autonomic neurones in the paraventricular nucleus of the hypothalamus. Curr. Neuropharmacol. 2011, 9, 262-277. [CrossRef]

30. Boll, S.; Almeida de Minas, A.C.; Raftogianni, A.; Herpertz, S.C.; Grinevich, V. Oxytocin and Pain Perception: From Animal Models to Human Research. Neuroscience 2018, 387, 149-161. [CrossRef]

31. Daniel, S.; Quintana, D.S.; Kemp, A.H.; Alvares, G.A.; Guastella, A.J. A role for autonomic cardiac control in the effects of oxytocin on social behavior and psychiatric illness. Front Neurosci. 2013, 7, 48. [CrossRef]

32. Dos Santos Junior, E.D.; Da Silva, A.V.; Da, K.R.T.; Haemmerle, C.A.S.; Batagello, D.S.; Da Silva, J.M.; Lima, L.B.; Da Silva, R.J.; Diniz, G.B.; Sita, L.V.; et al. The centrally projecting Edinger-Westphal nucleus-I: Efferents in the rat brain. J. Chem. Neuroanat. 2015, 68, 22-38. [CrossRef]

33. Buijs, R.M. Intra- and extrahypothalamic vasopressin and oxytocin pathways in the rat. Pathways to the limbic system, medulla oblongata and spinal cord. Cell Tissue Res. 1978, 192, 423-435. [CrossRef]

34. Eliava, M.; Melchior, M.; Knobloch-Bollmann, H.S.; Wahis, J.; da Silva Gouveia, M.; Tang, Y.; Ciobanu, A.C.; del Rio, R.T.; Roth, L.C.; Althammer, F.; et al. A New Population of Parvocellular Oxytocin Neurons Controlling Magnocellular Neuron Activity and Inflammatory Pain Processing. Neuron 2016, 89, 1291-1304. [CrossRef]

35. Wrobel, L.; Schorscher-Peten, A.; Dupré, A.; Yoshida, M.; Nishimori, K.; Tribollet, E. Distribution and identity of neurons expressing the oxytocin-receptor in the mouse spinal cord. Neurosci. Lett. 2011, 495, 49-54. [CrossRef]

36. Kret, M.E.; De Dreu, C.K.W. Pupil-mimicry condition trust in partners: Modration by oxytocin and group membership. Proc. R. Soc. B Biol. Sci. 2017. [CrossRef]

37. Horowitz, J.; Sears, M. Neurohypophyseal peptides and the eye: Use of synthetic analogs in analyzing effects on the pupil. Graefe's Arch. Clin. Exp. Ophthalmol. 1983, 220, 253-256. [CrossRef] 